\title{
Norske politiansattes deltakelse i arrestasjoner av jøder
}

\section{The Norwegian Police and Their Participation in the Arrests of Jews}

\author{
Therese Alvik
}

\begin{abstract}
The article refers to Norway during World War II. The Norwegian police have received criticism for their active role regarding the arrests of Jews who were living in Norway. In 2012, police director Odd Reidar Humlegård offered a public apology on behalf of the police. Police Administration employees accounted for a diverse group and there are examples of police officers who tried to avert the arrests. This theme is illustrated to clarify further the situation in a specific Norwegian city and for one Jewish family.
\end{abstract}

\section{Keywords}

WWII Norway, Norwegian police arrests of Jews, Holocaust, Ålesund 
Norsk politi spilte en aktiv rolle ved arrestasjoner og deportasjoner av norske jøder under andre verdenskrig. Denne artikkelen vil belyse sider av situasjonen, avgrenset til en jødisk familie og enkelte ansatte ved ett lokalt politikammer i Norge. Historien som her skildres er både unik og generell. Unik på grunn av sin veldig personlige karakter. Samtidig viser historien til den praksis som alle politikammer ble beordret til å følge vedrørende arrestasjoner av jøder.

Det var ikke tyske soldater, men det norske politiet, som fikk i oppgave å arrestere jødiske personer med opphold i Norge. Politietaten har i ettertid mottatt kritikk for sin deltakelse og for manglende vilje til å ta et oppgjør med sin egen fortid. Lyriker og forfatter Jan Erik Vold har vært en tydelig stemme i denne sammenheng. Han har gått offentlig ut og kritisert politiet for den tilsynelatende passiviteten de har vist angående temaet. ${ }^{1}$

De siste årene har dette bildet forandret seg noe. Det har kommet beklagelser fra flere representanter for det offentlige Norge. NSB (norske statsbaner) og norske myndigheter har beklaget sin deltakelse. I 2012, sytti år etter deportasjonene, gikk også politidirektør Odd Reidar Humlegård ut med en offentlig unnskyldning:

I forbindelse med 70-års markeringen for fangetransporten med skipet „Donau“ er det naturlig at jeg $i$ dag beklager at norsk politi medvirket til deportasjonen av norske jøder til konsentrasjonsleirene, sier politidirektør Odd Reidar Humlegård. - Dette var helt uskyldige mennesker som ble utsatt for grusomme handlinger, og det har påfort overlevende og etterlatte mye smerte. ${ }^{2}$

Den jødiske minoriteten utgjorde ca. 2100 personer i 1940. Dette tallet inkluderer jødiske flyktninger fra andre europeiske land. Norge føltes som en trygg utpost i Europa, i alle fall tryggere enn Sentral-Europa. Fra høsten 1942 til februar 1943 ble 772 jøder sendt fra Norge til konsentrasjonsleirer, kun 34 av disse overlevde pinslene. Bak tallet 772 jøder skjuler det seg like mange personlige historier. Disse historiene var i lang tid ukjente for den ikke-jødiske delen av befolkningen. I Norge var det i flere tiår en stor stillhet rundt Holocaust og jødeforfølgelsene i landet, særlig knyttet til de helt personlige historiene. Dette har gradvis endret seg etter som tiden har skapt en viss distanse til hendelsene. Med flere historier økes også kunnskapen og forståelsen for variasjoner innen den felles nasjonale historiebanken. Mitt kildearbeid i forbindelse med boken Familien Steinfeld. Da byen gråt (Selja forlag, 2013) førte til oppdagelsen av slike viktige personlige historier.

\section{Familien Steinfeld}

De fleste norske jødene valgte å bosette seg i Oslo og Trondheim. Det var i disse to byene at landets synagoger befant seg, og en sentralisering førte til muligheter for å holde ved like jødiske tradisjoner. Noen valgte imidlertid å utforske mulighetene i andre deler av landet. Ålesund er en liten by som ligger ved kysten på Nord-Vestlandet. Her bodde kun

1 www.dagsavisen.no/kultur/en-skamplett-for-norsk-politi-1.469378 (08.06.16)

2 https://www.politi.no/politidirektoratet/aktuelt/nyhetsarkiv/2012_11/Nyhet_11923.xml (08.06.16) 
én norsk-jødisk familie ved utbruddet av andre verdenskrig. Familien Steinfeld hadde etablert seg midt i byens sentrum og drev den anerkjente forretningen «Steinfelds magasin». Faren i huset, Israel Steinfeld, kom til Ålesund som 16-åring. Han trivdes godt og fikk snart et stort sosialt nettverk blant jevnaldrende. Israel var idrettsmann og benyttet flittig den vakre og varierte naturen som karakteriserer denne delen av landet. Israel ga tydelig uttrykk for sin norske identitet. Han følte seg på alle måter som norsk. Familien hans kom til landet som immigranter da Israel var tre år. Israel fortsatte å leve ut sine mål og drømmer i Ålesund. Han ble gift med Lea (født Levin) og på 1920-tallet fikk de barna Reidun og Morten. Forretningsvirksomheten ble stadig mer vellykket og fremtiden så lys ut. Familien Steinfeld var jøder, men det var ikke noe som vakte oppsikt i nærmiljøet. For ålesundere flest var de først og fremst venner, naboer, klassekamerater etc. Det faktum at de var jøder, var en del av deres identitet, men ikke noe som skilte dem ut fra Ålesunds andre innbyggere. Dette bildet skulle endre seg dramatisk som følge av den tyske invasjonen i 1940. Det året fylte Morten Steinfeld 15 år. For ham tok den ukompliserte og sorgløse ungdomstiden snart slutt. I starten av krigen kunne imidlertid Morten, i likhet med andre jøder, leve noen lunde som normalt. Trakasseringen økte gradvis. I 1941 ble vinduene til «Steinfelds magasin» tilgriset med hakekors og ordene «jude og jøde». Familien Steinfeld måtte tåle ukvemsord fra personer med Nazi-sympatier og Israel måtte stadig inn til avhør. På denne tiden forsøkte vennene deres å overtale dem til å rømme. Familien var usikker på hva som var beste løsning. Kanskje var en flukt et farligere alternativ enn å bli værende. Israel Steinfeld uttalte ofte: « $J e g$ er norsk statsborger. Jeg har ikke gjort noe galt. Jeg har intet å frykte.» Israel var overbevist om at hans norske statsborgerskap var en garanti for hans trygghet. Han hadde brukt 5 år med korrespondanse, advokathjelp og byråkrati før han i 1920 endelig mottok papiret som bekreftet at han med rette kunne kalle seg norsk ${ }^{3}$.

Så bikket kalenderen januar 1942 og livene til norske jøder tok en dramatisk vending. Det norske politiet fikk en ny oppgave. Alle norske jøder ble beordret til sitt lokale lensmannskontor for å få stemplet bokstaven J inn i identifikasjonspapirene sine. Etter kort tid ble den såkalte «jødeparagrafen» på nytt innført i Norges grunnlov. Ingen jøder hadde adgang til riket. I mai måned ble Israel Steinfeld arrestert, ${ }^{4}$ og han slapp ikke ut igjen.

\section{Politiet i Ålesund}

Under andre verdenskrig fikk Ålesund raskt tilnavnet «lille-London» av NS-medlemmer og tyske okkupanter. Årsaken var at byens innbyggere viste ekstra stor motstand mot den tyske invasjonen av landet. Det ble trykt og distribuert illegale aviser og det var ofte konfrontasjoner mellom NS-sympatisører og deres motstandere. Fra Ålesunds havner gikk båter til Storbritannia med flyktninger ombord, den såkalte «englandsfarten». På tilbakereisen var lasten byttet ut med våpen til bruk i motstandsarbeidet. Politikontoret

3 Riksarkivet, Justisdepartementet, Kommunalkontor K, Statsborgersaker 1920

4 Statsarkivet i Trondheim, Ålesund kretsfengsels arkiv 
spilte en viktig rolle i disse operasjonene. Mange ansatte var aktive i det illegale arbeidet. Nesten ingen av politiets ansatte hadde så langt meldt seg inn i NS. Det sies at personer møtte opp på politikontoret med pakket ryggsekk for å få opplysninger om når og hvor neste illegale transport skulle gå til England. Denne ordningen fungerte godt i en periode. Etter hvert ble imidlertid arbeidet vanskeligere. Englandsfarten ble infiltrert av tyskvennlige nordmenn. Navn, ruter og planer ble avslørt. Det resulterte også i at to lokale politimenn ble arrestert og senere henrettet. Tyske okkupasjonsmyndigheter og norske støttespillere satte i gang tiltak for å få kontroll over situasjonen. De fryktet at englandsfarten var vellykket på grunn av unnfallenhet fra politiet, eller kanskje også direkte sabotasje fra politiets side. ${ }^{5}$ Det var avgjørende å ha et lokalt politi som opptrådde lojalt overfor tyske planer og retningslinjer. I mars 1942 fikk Ålesunds innbyggere merke at ting var i ferd med å forandre seg drastisk. Reichskommisar Josef Terboven reiste personlig til byen sammen med blant annet politiminister Jonas Lie. Alle ansatte i politiet ble kommandert ut på gaten. Der ble det holdt «tordentaler» med trusler mot både politi og lokalbefolkning. Advarselen var tydelig nok. Ålesund skulle utslettes dersom forandringene ikke ble godtatt. ${ }^{6}$ Fotografier fra hendelsen viser at det var møtt opp mange skuelystne som ønsket å vite hva som foregikk. Politiets ansatte fikk beskjed om å melde seg inn i NS. Samme dag ble en stor andel av politistyrken oppsagt. Av de som fikk fortsette, var det kun tre-fire personer som ikke hadde fulgt pålegget og meldt seg inn i NS. De oppsagte ble erstattet med betrodde NS-medlemmer. Noen av de nyansatte kom fra andre deler av landet, noen ble beordret til Ålesund. ${ }^{7}$ Dette forandret politikorpset drastisk. Øystein Hetland, forsker ved Senter for studier av Holocaust og livssynsminoriteter, jobber for tiden med å finne ut mer om det norske politiet under krigen. Han viser til at 78 prosent av de politiansatte ved krigsslutt var kommet til under okkupasjonen.

«Det vi så var en etat som i stor grad var skiftet ut. Personalpolitikken under krigen skulle sørge for at flest mulig nazister ble politimenn, mens man fjernet politiske motstandere. Samtidig våket Gestapo over politifolkene, med makt til når som helst å gripe inn $i$ deres daglige liv og arbeide dersom de trådde feil. I ytterste fall arresterte Gestapo politifolk og sendte dem til konsentrasjonsleirer hvis de ble oppfattet som motstandsfolk,» sier Hetland. ${ }^{8}$

Utskiftningen førte også til en umiddelbar synlig endring for byens befolkning. De nye politimennene hadde grønne uniformer som skilte seg fra de tradisjonelle svarte. Et klart signal om at endringer skulle tvinges frem.

5 Danielsen og Larsen (red): Fra ide til dom. Universitetsforlaget, 1976. s. 177

$6 \quad$ Sunnmøre arbeideravis 22.03.1975

7 Jf. egen forskning av landssviksaker knyttet direkte til personer som var med på arrestasjonene av familien Steinfeld. Riksarkivet, Landssviksarkivet, N.N.

8 http://politiforum.no/no/nyheter/2015/oktober/Hjalp+folk+fra+innsiden.d25-T2BrU2X.ips $(08.06 .16)$ 


\section{Sigurd Refsnæs}

Blant de få politiansatte fra den opprinnelige staben, finner vi en svært ung og uerfaren politibetjent. Sigurd Refsnæs vokste opp i Ålesund. Hans foreldre var nære venner av Lea og Israel Steinfeld og Sigurd kjente hele den jødiske familien godt. De hadde vært en del av hans oppvekst. Familiene møttes ofte i sosiale anledninger, dro sammen på utflukter i regionen og var en naturlig del av hverandres hverdag.

Sigurd spilte etter hvert en av hovedrollene i et drama han selv ikke hadde drømt om å oppsøke. Da Norge ble okkupert, var Sigurd 25 år. Han hadde flyttet til Oslo, noe som ga nye muligheter, ikke minst når det gjaldt studier. Han var interessert i språk og lekte med tanken om å skaffe seg en undervisningsstilling innen språkfag. Som et ledd i planene var han i gang med studier i tysk. Krigen tvang imidlertid frem andre prioriteringer og nye mål. Sigurd var med i kampene mot den tyske invasjonen i starten av okkupasjonen, men norske styrker måtte gi opp for overmakten. Det endte med at han reiste tilbake til fødebyen Ålesund og fikk en stilling ved det lokale politikontoret. Valget førte han inn i et nett av begivenheter han ikke hadde kunnet forutse. Han fikk jobb i politiet før den store utskiftingen i 1942. Unggutten hadde ikke meldt seg inn i NS, men fikk likevel beholde jobben. Sigurd har selv fortalt at det tyske sikkerhetspolitiet så på ham som en nyttig brikke ${ }^{9}$ I deres øyne var han en ung og medgjørlig betjent som de kunne bruke til sin fordel. Det var nyttig å ha en politibetjent som kunne snakke både tysk og norsk. De undervurderte hans kapasitet og ressurser. Sigurd Refsnæs ble betegnet som en sviker blant mange ålesundere, men som en lojal betjent av statspolitiet. For utenforstående var bildet enkelt - Sigurd valgte å være en ressurs for det tyske statspolitiet. Sannheten var en ganske annen. Unggutten hadde fått i oppdrag å organisere den lokale gruppen av Milorg, en militær motstandsorganisasjon som ble bygget opp i Norge i løpet av andre verdenskrig. Det ble dermed livsviktig for Sigurd å holde sin dobbeltrolle skult. Hans sønn har senere uttalt: «Min far balanserte ikke på en knivsegg, men på et barberblad». Gjennom sine tolkeoppdrag fikk Refsnæs informasjon som han brukte i sitt motstandsarbeid. Han kunne for eksempel varsle om rassiaer og advare personer som tyskerne hadde mistanker til. Etter hvert skulle hans kløkt og kunnskap bli avgjørende også for byens jødiske familie.

\section{Arrestasjoner}

Familien Steinfeld hadde fulgt ordren om å få sine identifikasjonspapirer stemplet med en to centimeter høy J. Israel var arrestert, situasjonen var preget av uro og forvirring. 26. oktober var Lea Steinfelds fødselsdag. I året 1942 ble denne datoen preget av alt annet enn hyggelige begivenheter for Ålesunds jødiske familie. Dette var datoen for massearrestasjoner av jødiske menn. I realiteten var det også snakk om barn. Arrestordren gjaldt alle gutter over 15 år, blant dem Morten Steinfeld, som hadde rukket å bli 17 år

$9 \quad$ Sunnmøre arbeideravis, Intervju av Sigurd Refsnæs, 22.03.1975 
den sommeren. Over hele landet fikk norske politimenn ordre om å arrestere sine jødiske landsmenn. I Ålesund skrev Sigurd Refsnæs sin signatur på rapporten som senere ble levert til politimesteren og statspolitiet ${ }^{10}$. Det kan ikke slås fast om han fikk ordren eller selv skaffet seg dette oppdraget. Det er stor sannsynlighet for at Refsnæs sørget for at nettopp denne jobben ble hans. I forkant hadde han alliert seg med leger ved byens sykehus og kommet frem til en plan for å hindre arrestasjon. I rapporten han skrev, kan vi lese at Morten ligger syk hjemme. Vedlagt ligger de nødvendige legeerklæringer. Morten var ikke syk. Dette var politibetjentens måte å forhindre at Morten skulle arresteres. Tiden skulle vise at mer dramatikk var i vente. Det kom nye ordrer om at Morten skulle arresteres og transporteres til Oslo. Den 20. november 1942 ble Morten innlagt på Ålesund sykehus og operert for blindtarmbetennelse. Morten var fortsatt ikke syk. Hans hjelpere gjorde hva de kunne for å forhindre en arrestasjon. En operasjon av blindtarmen var nok til å holde statspolitiet unna og samtidig ville ikke Mortens fysiske helse bli skadet nevneverdig. Statspolitiet ble utålmodige og forlangte svar på hvorfor den unge jødiske gutten fortsatt befant seg i Ålesund. Så kom neste arrestasjonsbølge. Den 26. november, en måned etter at mennene ble arrestert, kom ordren om at nå skulle kvinner og barn arresteres. Denne gangen ble det ikke satt noen begrensninger. Alle jøder skulle arresteres. Sigurd Refsnæs og hans hjelpere fortsatte sitt iherdige arbeid. Det ble sendt ny rapport om at Morten fortsatt lå på sykehuset og ikke kunne flyttes. Hans mor og søster unngikk en arrestasjon i november. Statspolitiet bestemte at de alle tre skulle fraktes til Oslo så snart Morten var i stand til å foreta reisen. Lea Steinfelds venninne har uttalt at byens politimester, Arne Håkenrud, var ivrig i jobben med å få jødene arrestert ${ }^{11}$. Telegram ble sendt mellom han og statspolitiet angående hvorvidt Morten kunne arresteres. Morten hjelpere lyktes lenge med å unngå arrestasjoner. Dragkampen fikk imidlertid en dramatisk slutt i februar 1943. Det nærmet seg siste «jødetransport» fra Norge og familiens hjelpere klarte ikke lenger å holde statspolitiet unna. Arrestasjonen var et faktum. Mandag 22. februar skrev Ålesund politikammer ut arrestordrer på Morten, Reidun og Lea. Statspolitiet hadde beordret dem transportert til Oslo.

I Ålesund, som i resten av landet, stod det lokale politiet for selve arrestasjonen. Denne gangen var det ikke Sigurd Refsnæs som banket på døren i Rasmus Rønnebergs gate. Det var to norske politibetjenter ikledd den grønne uniformen, betjenter som var medlemmer av NS og som hadde blitt beordret til Ålesund i 1942. Morten, Reidun og Lea ble arrestert og ført til kaien like ved. Derfra foregikk den første etappen med rutebåt til Åndalsnes. Senere reiste det lille følget videre med tog til Oslo. Sigurd Refsnæs nektet imidlertid å gi opp alt håp. Han hadde organisert et fluktforsøk som skulle finne sted i løpet av togturen. Ved et stopp i Gudbrandsdalen måtte familien således sørge for å komme seg bort fra oppasserne, for så å bli hjulpet av lokale motstandsmenn. Lea, Reidun og Morten var informert om planene. Det viste seg imidlertid at stasjonen hadde ekstra vakthold denne dagen og fluktforsøket var ikke vellykket. Dermed kunne de to politiansatte fra Ålesund se sitt oppdrag fullført. Lea og ungdommene ble overlatt til

10 Riksarkivet, justisdepartementet, Tilbakeføringskontoret for inndratte formuer, Steinfeld Morten

11 Aalesunds museum, krigssamlingen, intervju av Anne Jangaard 
politiet i Oslo. Statspolitiet kunne se seg fornøyd med situasjonen. Ålesund var «jødefri».

Det siste livstegnet nådde Sigurd Refsnæs og andre venner noen uker etter arrestasjonen. Det kom som et postkort, sendt fra Reidun til kjæresten hennes. Kortet har avsenderadresse arbeidslager Auschwitz. Reidun skrev:

\section{«Kjereste Carsten. Har det bra. Håper på brev. \\ Hils alle. Reidun» ${ }^{12}$}

Reidun, Morten og Lea var allerede drept da kortet nådde frem til Ålesund. Deres far døde kort tid senere.

\section{Fred og oppgjør}

Ved krigens slutt fikk Ålesunds befolkning kjennskap til noen av politiets interne anliggender. Det ble fort klart at Sigurd Refsnæs slett ikke hadde hatt den rollen som de fleste var villedet til å tro. Refsnæs snakket ikke mye om sin egen situasjon under okkupasjonen, men deler av historien har likevel blitt rekonstruert ved hjelp av hans egne og andres bidrag. Det blir snakket med annerkjennelse om Sigurd Refsnæs innsats, både overfor familien Steinfeld og for mange andre personer som behøvde hans hjelp. Det lyktes ham ikke å redde sine jødiske venner, men ingen gjorde en større innsats for å fors $\varnothing$ ke nettopp det.

Etter krigens slutt begynte det såkalte landssvikoppgjøret. De to politibetjentene som arresterte familien Steinfeld ble begge tiltalt for landssvik. Arrestasjonen av Ålesunds jødiske familie er imidlertid ikke med i tiltalen ${ }^{13}$. Årsaken er sannsynligvis at de hadde gjort jobben de var satt til og handlet ut fra ordre. Ingen politimenn som deltok i arrestasjoner av jøder har senere stått frem med sine tanker og minner. Vi vet derfor ikke hva de selv i ettertid tenkte om sin egen medvirkning.

Også rollen til politibetjentenes overordnede, politimester Arne Håkenrud, ble endret i løpet av en dag. Han hadde ifølge Leas venninne jobbet for å få jødene arrestert. Plutselig var han selv i en utsatt posisjon. Følgende sitat sier noe om den helt spesielle situasjonen som utspant seg:

Da heimestyrkene $i$ Ålesund 7. mai 1945, klokka 24 begynte marsjen utover Borgundvegen for å overta etter tyskerne og arrestere nazipolitiet, gikk en av Ålesunds politimenn $i$ spissen. Det var Sigurd Refsnes, som hadde vart $i$ korpset og drevet illegalt arbeid under hele krigen. I politimesterboligen i Fjellgata ble NS-mannen, politimester Arne Håkenrud, arrestert. Hans siste kommando da heimestyrkene kom inn i huset, lød: «Ikke skyt! Jeg overgir meg.» ${ }^{14}$

12 Senter for studier av Holocaust og livssynsminoriteter, utstillingen

13 Riksarkivet, landssvikarkivet, N.N.

14 Vollan, Odd (1989) Den tause motstand. Ålesund, Nordvest forlag. S. 202 
Artikkelen viser eksempler på at offentlige tjenestemenn tok ulike valg. Dette på tross av felles regelverk og ordre. Rettsapparatet konkluderte med at politiansatte som deltok da jødene ble arrestert, ikke hadde begått en straffbar handling. De handlet etter ordre. Da politidirektør Humlegård i 2012 gikk ut med en offentlig beklagelse, så var dette på vegne av politietaten som helhet. I denne handlingen lå det en erkjennelse av ansvar og skyld. Det må bli opp til den enkelte å bedømme hva en slik beklagelse kan bety i dag.

\section{Litteraturliste:}

ALVIK, Therese (2013): Familien Steinfeld. Da byen gråt. Selja forlag.

DANIELSEN, Rolf og UGELVIK LARSEN, Stein (1976): Fra ide til dom. Noen trekk fra utviklingen av Nasjonal samling. Universitetsforlaget.

FLATMARK, Jan Olav og GRYTTEN, Harald (1988): Ålesund i hverdag og krig. Små og store hendelser fra de underlige åra 1940 - 1945. Ålesund, Nordvest Forlag A/S.

RINGDAL, Nils Johan (1987): Mellom barken og veden. Oslo, H. Aschehoug \& co.

VOLLAN, Odd (1989): Den tause motstand. Ålesund, Nordvest forlag.

\section{Andre kilder:}

Internett:

https://www.politi.no/politidirektoratet/aktuelt/nyhetsarkiv/2012_11/Nyhet_11923.xml http://www.dagsavisen.no/kultur/en-skamplett-for-norsk-politi-1.469378

Sunnmøre arbeideravis

Senter for studier av Holocaust og livssynsminoriteter

Riksarkivet

Statsarkivet i Trondheim

Aalesunds museum

Therese Alvik / Theresealvik@gmail.com

Lektor (med tilleggsutdanning), Ansatt i Nes kommune, Årnes skole, Runnivegen 24, 2150 Årnes, Norge 